\title{
Hollow fiber supported ionic liquid membrane microextraction for determination of sulfonamides in environmental water samples by high-performance liquid chromatography
}

\author{
Yong Tao ${ }^{\mathrm{a}, \mathrm{b}}$, Jing-Fu Liu ${ }^{\mathrm{b}}$, Xia-Lin $\mathrm{Hu}^{\mathrm{c}}$, Hong-Cheng $\mathrm{Li}^{\mathrm{b}}$, Thanh Wang ${ }^{\mathrm{b}}$, Gui-Bin Jiang ${ }^{\mathrm{a}, \mathrm{b}, *}$ \\ a School of Earth and Space Sciences, University of Science and Technology of China, Hefei 230026, China \\ ${ }^{\mathrm{b}}$ State Key Laboratory of Environmental Chemistry and Ecotoxicology, Research Center for Eco-Environmental Sciences, \\ Chinese Academy of Sciences, P.O. Box 2871, Beijing 100085, China \\ ${ }^{\mathrm{c}}$ College of Environmental Science and Engineering, Tongji University, Shanghai 200092, China
}

\section{A R T I C L E I N F O}

\section{Article history:}

Received 19 March 2009

Received in revised form 25 May 2009

Accepted 5 June 2009

Available online 11 June 2009

\section{Keywords:}

Ionic liquid

Supported liquid membrane

Liquid phase microextraction

High-performance liquid chromatography

Sulfonamides

\begin{abstract}
A B S T R A C T
By using ionic liquid as membrane liquid and tri-n-octylphosphine oxide (TOPO) as additive, hollow fiber supported liquid phase microextraction (HF-LPME) was developed for the determination of five sulfonamides in environmental water samples by high-performance liquid chromatography with ultraviolet detection The extraction solvent and the parameters affecting the extraction enrichment factor such as the type and amount of carrier, $\mathrm{pH}$ and volume ratio of donor phase and acceptor phase, extraction time, salt-out effect and matrix effect were optimized. Under the optimal extraction conditions (organic liquid membrane phase: [ $\left.\mathrm{C}_{8} \mathrm{MIM}\right]\left[\mathrm{PF}_{6}\right]$ with $14 \% \mathrm{TOPO}(\mathrm{w} / \mathrm{v})$; donor phase: $4 \mathrm{~mL}$, pH $4.5 \mathrm{KH}_{2} \mathrm{PO}_{4}$ with $2 \mathrm{M}$ $\mathrm{Na}_{2} \mathrm{SO}_{4}$; acceptor phase: $25 \mu \mathrm{L}, \mathrm{pH} 13 \mathrm{NaOH}$; extraction time: $\left.8 \mathrm{~h}\right)$, low detection limits $(0.1-0.4 \mu \mathrm{g} / \mathrm{L}$, $\mathrm{RSD} \leq 5 \%)$ and good linear range $\left(1-2000 \mathrm{ng} / \mathrm{mL}, R^{2} \geq 0.999\right)$ were obtained for all the analytes. The presence of humic acid $(0-25 \mathrm{mg} / \mathrm{L}$ dissolved organic carbon) and bovine serum albumin $(0-100 \mu \mathrm{g} / \mathrm{mL})$ had no significant effect on the extraction efficiency. Good spike recoveries over the range of $82.2-103.2 \%$ were obtained when applying the proposed method on five real environmental water samples. These results indicated that this present method was very sensitive and reliable with good repeatabilities and excellent clean-up in water samples. The proposed method confirmed hollow fiber supported ionic liquid membrane based LPME to be robust to monitoring trace levels of sulfadiazine, sulfamerazine, sulfamethazine, sulfadimethoxine and sulfamethoxazole in aqueous samples.
\end{abstract}

(c) 2009 Published by Elsevier B.V.

\section{Introduction}

Sulfonamides (SAs) belong to an important group of bacteriostatic agents used to prevent infections, treat diseases and to promote growth [1]. Due to their wide-ranging activity and low cost, SAs have been widely used in human and veterinary medicine. After normal applications, SAs and/or their metabolites can be excreted from human body or animal organisms through urine and feces [2]. Ultimately these residues can find their way into the environment and consequently, trace of SAs has been frequently detected in surface water worldwide $[3,4]$. Although SAs are present in the environment at low concentration levels, they can promote the

\footnotetext{
* Corresponding author at: State Key Laboratory of Environmental Chemistry and Ecotoxicology, Research Center for Eco-Environmental Sciences, Chinese Academy of Sciences, P.O. Box 2871, Beijing 100085, China. Tel.: +86 1062849334 ; fax: +861062849179.

E-mail address: gbjiang@rcees.ac.cn (G.-B. Jiang).
}

development of antibiotic-resistant bacteria, cause allergic reactions in human, and even possess carcinogenic potency [5,6]. In the research of Halling-Sørensen et al., SAs have a long life-time in the environment and can resist biodegradation and accumulate in all kinds of organisms through the food-chain. Further, photoenhanced toxicity of SAs are reported by Jung et al. [7]. Huang et al. suggested that SAs are the most common water pollutants among various antibiotics, based on their environmental fate and predicted concentrations [8]. Stringent guidelines have been established in the US and the EU to conduct environmental assessment of pharmaceutical compounds $[9,10]$. Therefore, it is imperative to develop reliable, highly sensitive and easily operated methods to monitor their concentrations in the environment.

In the past decades, various methods have been employed to determine sulfonamide drugs such as gas chromatography-mass spectrometry (GC-MS) [11,12], GC-atomic emission detection (GCAED) [13], high-performance liquid chromatography ultraviolet detection (HPLC-UV) [14,15] or fluorescence detection [16], liquid chromatography-mass spectrometry (LC-MS) [17], capillary 
electrophoresis-ultraviolet detection (CE-UV) [18], etc. Prior to GC analysis, derivatization of non-volatile and thermally labile sulfonamides is required. Although HPLC-fluorescence detection has been successfully applied to determine SAs with high sensitivity, derivatization is also required to enhance the fluorescence signal [16]. LC-MS [17] or HPLC-UV [14,15] seems to be the most promising methods since derivatization is not needed.

Sample preparation and clean-up in order to eliminate the interference of matrices for environmental samples is of great importance. Due to the very low concentrations of sulfonamide residues and the complexity of the matrices, an effective pretreatment approach is of vital importance for analysis of SAs prior to those quantitative chromatography-based techniques. Various sample preparation procedures have been applied for SAs, such as liquid-liquid extraction (LLE) [19,20] and on/off-line solid-phase extraction (SPE) $[16,21,22]$. These procedures are usually tedious and time-consuming, in addition to the large volume of sample and large consumption of toxic organic solvents required. In recent years, microextraction techniques were introduced as an alternative to the conventional SPE and LLE due to the simplicity of operation, solvent-saving/free and being time-efficient.

Since 1999, hollow fiber based LPME introduced by PedersenBjergaard and Rasmussen [23], have been widely applied as an alternative to conventional techniques mentioned above. Besides the advantages of preconcentration, sample clean-up, and solventsaving, this technique requires the equipment to be simple and inexpensive. And in the hollow fiber based LPME device, the extraction solvent is contained within the lumen of a porous hollow fiber, so the solvent is not in direct contact with the sample solution. Thus, the hollow fiber based LPME is a reliable and robust technique which can provide high enrichment and low limits of detection. To date, many works published have successfully applied the hollow fiber based LPME for extraction of several different classes of drugs from various matrices [24-27]. Final analysis of extraction solutions has been reported with CE [23], HPLC [28], GC-MS [29], and LC-MS [30].

For the hollow fiber based LPME, appropriate selection of the organic solvent is of great importance to obtain efficient extraction. Toluene, undecane, 1-octanol and dihexyl ether are the most popular solvents used in HF-LPME. Nevertheless, based on the "like dissolves like" principle in LPME and the amphoteric properties of SAs (Table 1), these traditional solvent might be not suitable for SAs. Room temperature ionic liquids (RTILs) are novel solvents that have good solubility for inorganic and organic compounds [31]. RTILs have displayed good extractability for various organic compounds and metal ions [32]. Moreover, with the properties of non-volatility and innocuity to chromatographic column, ionic liquids can be compatible with liquid phase chromatography and directly injected for analysis [33,34]. To our knowledge, the applicability of ionic liquids for extracting SAs has yet to be investigated. Previous studies [35,36] demonstrated that the ionic liquids could be firmly immobilized in the microspores of a supported membrane, thus it is attractive to explore the use of ionic liquid based liquid membrane extraction for SAs.

In this present work, three-phase hollow fiber supported ionic liquid membrane extraction was developed for preconcentration of trace levels of five sulfonamides in environmental water samples. Parameters including the organic membrane phase, the content of TOPO added in organic liquid, $\mathrm{pH}$ of donor phase and acceptor phase, volume ratio of donor to acceptor phase, extraction time, shaking speed and salinity of sample solution were optimized and the method performance was evaluated and was applied for extracting SAs in environmental water samples.

\section{Experimental}

\subsection{Reagents and materials}

Sulfadiazine (SD), sulfamerazine $\left(\mathrm{SM}_{1}\right)$, sulfamethazine $\left(\mathrm{SM}_{2}\right)$, sulfadimethoxine (SDM) and sulfamethoxazole (SMZ) with purity of $99.0 \%$ were purchased from Dr. Ehrenstorfer GmbH (Augsburg, Germany). 1-Octyl-3-methylimidazolium hexafluorophosphate $\left[\mathrm{C}_{8} \mathrm{MIM}\right]\left[\mathrm{PF}_{6}\right](99.0 \%)$ was purchased from Meisibei Co., Ltd. (Shanghai, China). Dihexyl ether (DHE) was purchased from Tokyo Kasei Kogyo Co., Ltd. (Kita-Ku, Tokyo, Japan). Tri-n-octylphosphine oxide (TOPO), undecane and terrestrial origin humic acid sodium salt with $35.1 \%$ of dissolved organic carbon (DOC) were purchased from Sigma-Aldrich (Steinheim, Germany) and used as obtained. Bovine serum albumin (BSA) (total protein 99\%) was obtained from Xinjingke Biotechnology Co., Ltd. (Beijing, China). HPLC-grade methanol was purchased from Mallinckrodt Baker (Phillipsburg, NJ, USA). All other chemicals were of analytical grade or above and ultrapure water, prepared by an Easypure LF purification system (Barnstead International, Dubuque, IA, USA), was used throughout.

Individual standard stock solutions of SAs were prepared by dissolving $50 \mathrm{mg}$ standard in $100 \mathrm{~mL}$ of HPLC-grade methanol. Working solutions were prepared by appropriate dilution of the stock solutions with water. The standard stock solutions and work-

Table 1

Target sulfonamide antibiotics structures and physicochemical properties

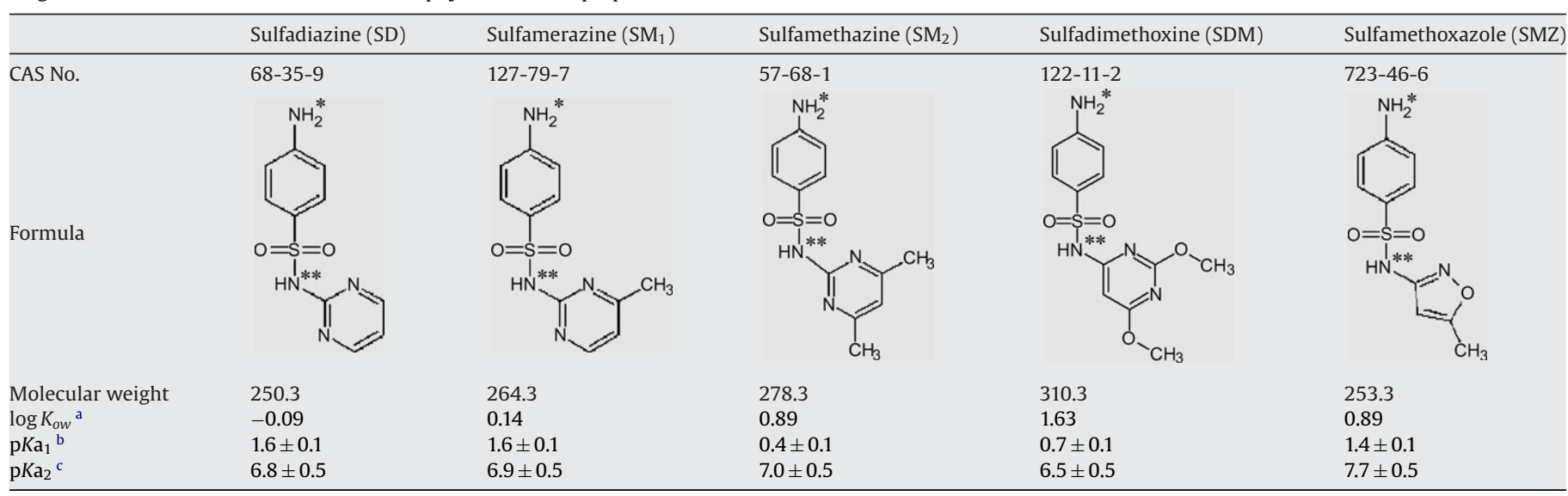

a $\log K_{\text {ow }}$ and $\mathrm{pKa}$ are calculated using the $\mathrm{ACD} / \mathrm{pKa}$ and $\mathrm{ACD} / \log P \mathrm{DB}$ soft programs (Advanced Chemistry Development, Toronto, Canada).

b $\mathrm{pKa}_{1}$ is the dissociation constant of the amino group which is the basic dissociation constant.

c $\mathrm{pKa}_{2}$ is the dissociation constant of sulfanilamido group which is the acidic dissociation constant. 
ing solution were stored at $4{ }^{\circ} \mathrm{C}$ in refrigerator, but thawed to room temperature before use.

Q3/2 Accurel $^{\circledR}$ PP polypropylene microporous hollow fiber membrane (200 $\mu \mathrm{m}$ wall thickness, $600 \mu \mathrm{m}$ inner diameter, $0.2 \mu \mathrm{m}$ pore size, $75 \%$ porosity) was obtained from Membrana $\mathrm{GmbH}$ (Wuppertal, Germany). Aseptic Syringe (with a needle of $0.6 \mathrm{~mm}$ outer diameter and $25 \mathrm{~mm}$ length, $1 \mathrm{~mL}$ ) for single use, obtained from Shoukang Medical Instrument Co., Ltd (Shanghai, China) was used to fill the acceptor solution into the lumen of the hollow fiber for extraction and to flush out the acceptor phase.

\subsection{Instrument}

Chromatographic analysis was performed in Agilent 1100 series HPLC system (Wilmington, DE, USA), consisting of G1312A binary pump and G1314 VW detector. All separations were achieved on an analytical reversed-phase column (Eclipse $\mathrm{XDB}^{-\mathrm{C}_{18}}$ column, $150 \mathrm{~mm} \times 4.6 \mathrm{~mm}$, particle size $5 \mu \mathrm{m}$ ) under isocratic conditions at column temperature of $25^{\circ} \mathrm{C}$. The mobile phase was a mixture of acetonitrile and $\mathrm{pH} 5.5 \mathrm{KH}_{2} \mathrm{PO}_{4}-\mathrm{K}_{2} \mathrm{HPO}_{4}$ buffer $(20 \mathrm{mmol} / \mathrm{L})$ at a flow rate of $1 \mathrm{~mL} / \mathrm{min}$. The ultraviolet detector was operated at $265 \mathrm{~nm}$. Gradient elution program used was the following: initial concentration of acetonitrile at $95 \%$, linearly decreasing to $75 \%$ in 0-3 min, linearly decreasing to $60 \%$ in $3-7$ min and then linearly decreasing to $35 \%$ in $7-9 \mathrm{~min}$ and maintaining at $35 \%$ for $1 \mathrm{~min}$. The five SAs were baseline separated and eluted within $10 \mathrm{~min}$.

\subsection{Water samples}

Five environmental water samples including wastewater from pig, fish and duck farm, and paddy water and river water were collected for validating the proposed method. River water sample was collected from Tiaoxi river in north of Zhejiang province. The other water samples were collected from suburbs of Hangzhou city. All samples were collected in September 2008. The collected waters were maintained in brown glass bottles and stored at $4{ }^{\circ} \mathrm{C}$. Before extraction, the water samples were adjusted to $\mathrm{pH} 4.5$ with the addition of $0.02 \mathrm{M} \mathrm{KH}_{2} \mathrm{PO}_{4}$ at room temperature.

\subsection{Extraction procedure}

The HF-LPME unit set-up used was similar to the one described in previous work by Lezamiz and Jönsson [37]. In brief, the hollow fiber $(13 \mathrm{~cm})$ was cleaned with acetone by ultrasonication and air dried before use. The lumen of the fiber used was filled with water, and then the fiber was dipped into the membrane liquid $\left(\left[\mathrm{C}_{8} \mathrm{MIM}\right]\left[\mathrm{PF}_{6}\right]\right.$ with $14 \%(\mathrm{w} / \mathrm{v}) \mathrm{TOPO}$ ) for $5 \mathrm{~min}$ to form the organic liquid membrane in the fiber pores. Before extraction, the surface and lumen of the fiber were flushed with water to remove excess membrane liquid. The acceptor phase ( $\mathrm{pH} 13 \mathrm{NaOH}$ ) was slowly injected into the fiber lumen by a disposable syringe until the lumen was full. Then two ends of the fiber were folded and sealed with aluminum foil. The prepared extraction set-up had an effective length of $12 \mathrm{~cm}$ and the corresponding volume of acceptor was $25 \mu \mathrm{L}$. After that, the set-up was placed and submerged into the donor phase $\left(0.02 \mathrm{M} \mathrm{KH}_{2} \mathrm{PO}_{4}, \mathrm{pH} 4.5\right)$. The whole extraction was performed in a 5 -mL brown capped vial with $8 \mathrm{~h}$ shaking at 300 rpm on multipurpose desk homothermal shaker (DDHZ-300, Taicang Experimental Instrument Factory, Jiangsu, China). At the end of the extraction time, the fiber was carefully removed from the sample solution and both sealed ends were cut. One end was connected to the needle of Aseptic Syringe full of air and the acceptor phase containing the target analytes was flushed out from the fiber lumen into a clean glass liner tube ( $100 \mu \mathrm{L}$, Alltech, Deerfield, IL, USA). Finally, the whole acceptor phase $(\sim 25 \mu \mathrm{L})$ was manually injected into HPLC system for analysis. In order that the extraction was free of memory effects, and the membrane life was not a concern, a new fiber was used for each extraction.

Optimization of the extraction parameters were performed with sample solutions spiked with $5 \mu \mathrm{g} / \mathrm{L}$ of five sulfonamide compounds. All experiments were replicated three times and the mean values were obtained.

\subsection{Calibration and data processing}

The operation of the extraction was evaluated by the concentration enrichment factor $(E F)$ :

$E F=\frac{C_{A P, \text { final }}}{C_{D P, \text { initial }}}$

where $C_{D P \text {, initial }}$ and $C_{A P \text {, final }}$ are the initial analyte concentration in the donor phase (DP) and the final analyte concentration in the acceptor phase (AP), respectively. $C_{A P \text {, final }}$ was calculated from the calibration curves by directly injecting $20 \mu \mathrm{L}$ of different concentrations of standards into the HPLC system. The concentrations of analytes in environmental samples were determined by the proposed procedure and calculated from the standard curve. All results were expressed as mean values of at least three replicates.

\section{Results and discussion}

\subsection{Selection of liquid membrane}

Generally, there are several selection criteria for organic solvents as the liquid membrane: (1) immobility in the pores of hollow fiber; (2) immiscibility with water; (3) reasonably higher solubility of analytes in the organic phase than in the aqueous phase. Based on those main requirements, three organic solvents including $n$-undecane, DHE and $\left[\mathrm{C}_{8} \mathrm{MIM}_{\mathrm{P}} \mathrm{PF}_{6}\right.$ were tested at fixed conditions as follows: $4 \mathrm{~mL}, \mathrm{pH} 4.5 \mathrm{KH}_{2} \mathrm{PO}_{4}$ buffer solution as DP, $10 \mu \mathrm{L}, 0.1 \mathrm{M} \mathrm{NaOH}$ as AP, shaking speed $100 \mathrm{rpm}$ and $1 \mathrm{~h}$ of extraction time. As shown in Table 2 , when $n$-undecane, a nonpolar organic solvent, was used, none of the five sulfonamides compounds was extracted into AP; When DHE with weakly polar solvent was used, the enrichment of all the five compounds was improved, but the EF (3.3-9.1) was unacceptable. Comparatively, $\left[\mathrm{C}_{8} \mathrm{MIM}\right] \mathrm{PF}_{6}$ with higher polarity could provide relative high $E F$ (4.5-12.5). The phenomena were in good agreement with the principle of "like dissolving like". As SAs belong to the polar compounds, $\left[\mathrm{C}_{8} \mathrm{MIM}\right] \mathrm{PF}_{6}$ with higher polarity than DHE would be more applicable as the extraction solvent. On the other hand, as sulfonamides are hydrophilic drugs $\left(\log K_{o w}<1\right)$ with high solubility in aqueous media, their direct extraction by passive diffusion from the DP through the organic membrane immobilized in the fiber pores into AP would be very difficult. To obtain higher $E F$, the commonly-used additives, TOPO [38-40] and Aliquat 336 [41,42], were dissolved into the organic solvents in membrane liquid, which would change the behavior of the membrane liquid. The results (Table 2) showed more efficient extraction in the presence of TOPO dissolved in $\left[\mathrm{C}_{8} \mathrm{MIM}\right] \mathrm{PF}_{6}$, i.e. the $E F$ s doubled compared to that in pure $\left[\mathrm{C}_{8} \mathrm{MIM}\right] \mathrm{PF}_{6}$. Fortunato et al. demonstrated that no leakage of ionic liquid from membrane pores was found and the ionic liquid membrane showed high operational stability [43]. Thus, the mixture of $\left[\mathrm{C}_{8} \mathrm{MIM}\right] \mathrm{PF}_{6} / \mathrm{TOPO}$ was selected as membrane liquid in subsequent experiments.

Following that, the influence of TOPO concentration in membrane liquid on $E F$ was further studied. Fig. 1 shows EFs of all sulfonamide compounds increased with increase of TOPO content and reached maximum at $14 \%$ TOPO in $\left[\mathrm{C}_{8} \mathrm{MIM}\right] \mathrm{PF}_{6}$. In this case, more addition of TOPO into $\left[\mathrm{C}_{8} \mathrm{MIM}\right] \mathrm{PF}_{6}$ would become insoluble and result in the non-homogeneity of the membrane liquid. 
Table 2

Extraction enrichment factor $(E F)$ of different organic solvents as membrane liquid.

\begin{tabular}{|c|c|c|c|c|c|}
\hline Organic membranes & SD & $\mathrm{SM}_{1}$ & $\mathrm{SM}_{2}$ & SMZ & SDM \\
\hline DHE & 3.3 & 3.9 & 4.8 & 9.0 & 9.1 \\
\hline n-Undecane & - & - & - & - & - \\
\hline$\left[\mathrm{C}_{8} \mathrm{MIM}\right]\left[\mathrm{PF}_{6}\right]$ & 4.5 & 5.6 & 5.5 & 12.5 & 11.2 \\
\hline DHE/4\% TOPO & 4.2 & 4.3 & 5.1 & 12.4 & 12.2 \\
\hline n-Undecane/4\% TOPO & 1.6 & 2.1 & 1.8 & 2.5 & 3.7 \\
\hline$\left[\mathrm{C}_{8} \mathrm{MIM}\right]\left[\mathrm{PF}_{6}\right] / 4 \% \mathrm{TOPO}$ & 7.7 & 8.5 & 9.1 & 17.0 & 20.8 \\
\hline DHE/4\% Aliquat 336 & 3.1 & 3.5 & 4.7 & 8.6 & 10.4 \\
\hline n-Undecane/4\% Aliquat 336 & - & - & - & - & - \\
\hline$\left[\mathrm{C}_{8} \mathrm{MIM}\right]\left[\mathrm{PF}_{6}\right] / 4 \%$ Aliquat 336 & 3.9 & 5.0 & 4.1 & 7.2 & 8.3 \\
\hline
\end{tabular}

DP: $4 \mathrm{~mL}$, pH $4.5 \mathrm{KH}_{2} \mathrm{PO}_{4}$ solution spiked with $5 \mu \mathrm{g} / \mathrm{L}$ target compounds; AP: $10 \mu \mathrm{L}, 0.1 \mathrm{M} \mathrm{NaOH}$; stirring speed: $100 \mathrm{rpm}$; extraction time: $1 \mathrm{~h}$.

Accordingly, the extraction flux would be reduced from DP into AP. Therefore, $14 \%$ TOPO was adopted for further studies.

\subsection{Effect of donor and acceptor $\mathrm{pH}$}

SAs are ampholytes, and in order to efficiently extract them into the organic membrane liquid, the properties of DP should be adjusted for SAs to be in their neutral forms. In our experiment, $\mathrm{pH}$ of DP in the range of 1-7 was studied using two systems with the constant volume of $4 \mathrm{~mL}$ : (1) the buffer solution of $\mathrm{KH}_{2} \mathrm{PO}_{4}$; (2) the solution of $\mathrm{HCl}$. The $\mathrm{pH}$ value of DP was adjusted to the test value by $5 \mathrm{~mol} / \mathrm{L} \mathrm{HCl}$ and $\mathrm{NaOH}$. The results showed that the same trends of changes were obtained by two kinds of DP solutions and the maximum extraction efficiency was obtained at $\mathrm{pH} 4.5$ of $\mathrm{KH}_{2} \mathrm{PO}_{4}$, as shown in Fig. 2a. The probably reasons might be concerned with the ampholyte property of SAs. In view of properties of the five target analytes (Table 1), the presence of the amino group and the sulfanilamido group would cause a two-step protolysis and increase their hydrophilicity, impeding their direct extraction into hydrophobic media $\left(\log K_{o w}<1\right)$. Theoretically it is feasible to control the ionizing and non-ionizing forms of SAs by adjusting the $\mathrm{pH}$. In addition, the hydrophobicity of the neutral species is logically greater than that of their corresponding ions [44]. When $\mathrm{pH}$ is adjusted to the average of $\mathrm{pKa} \mathrm{a}_{1}$ and $\mathrm{pKa} \mathrm{a}_{2}$ of SAs, the neutral molecule form is the dominant species [14]. Therefore, the hydrophilic-hydrophobic character of sulfonamides can be changed by adjusting the $\mathrm{pH}$. Like other hydrophilic pharmaceutical residues, such as salbutamol and terbutaline [41], SAs might also be extracted by three-phase HF-LPME. As mentioned above, $\mathrm{pH}$ of DP might be adjusted to the average of $\mathrm{pKa} \mathrm{a}_{1}$ and $\mathrm{pKa} \mathrm{a}_{2}$ of the target SAs to convert them into their

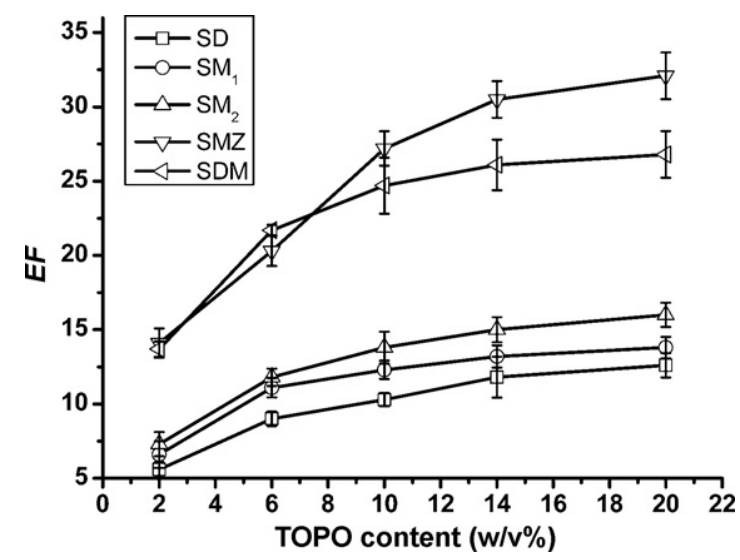

Fig. 1. Effect of TOPO content on the extraction enrichment factor. DP: $4 \mathrm{~mL}$, pH 4.5 $\mathrm{KH}_{2} \mathrm{PO}_{4}$ buffer solution; AP: $10 \mu \mathrm{L}, 0.1 \mathrm{M} \mathrm{NaOH}$; liquid membrane: [ $\left.\mathrm{C}_{8} \mathrm{MIM}\right]\left[\mathrm{PF}_{6}\right.$ ] with TOPO; shaking speed: $100 \mathrm{rpm}$; extraction time: $1 \mathrm{~h}$. ( $\square) \mathrm{SD} ;(\bigcirc) \mathrm{SM}_{1} ;(\triangle) \mathrm{SM}_{2}$; $(\nabla) \mathrm{SMZ} ;(\triangleleft) \mathrm{SDM}$. neutral species. $\mathrm{p} K \mathrm{a}_{1}$ and $\mathrm{p} K \mathrm{a}_{2}$ of analytes are in the range of $0.4 \pm 0.1$ to $1.6 \pm 0.1$ and $6.5 \pm 0.5$ to $7.7 \pm 0.5$, respectively (Table 1 ). Accordingly, $\mathrm{KH}_{2} \mathrm{PO}_{4}$ at $\mathrm{pH} 4.5$ was used as DP in subsequent experiments.

Based on the extraction principles of HF-LPME, the pH of AP should ionize the trapped analytes to prevent them from being back-extracted into the liquid membrane. When $\mathrm{KH}_{2} \mathrm{PO}_{4}$ of $\mathrm{pH} 4.5$ was adopted as DP, pH over 10 should be adopted for AP. The acceptor concentration of $\mathrm{NaOH}$ was further optimized in the range of 0.001-2 M. As the results in Fig. 2b indicated, maximum EFs were obtained at $0.25 \mathrm{M} \mathrm{NaOH}$ as AP. Subsequently, EFs decreased with the increase of the concentration of $\mathrm{NaOH}$ over $0.25 \mathrm{M}$. The probable reason was that excess concentration of $\mathrm{NaOH}$ leaked into DP and weakened the DP capability to convert SAs into neutral species. In the following experiments, $0.25 \mathrm{M} \mathrm{NaOH}$ was used as acceptor solution.

\subsection{Effect of volume ratio of donor to acceptor}

In three-phase HF-LPME, the analytes are extracted by passive diffusion from the aqueous donor phase, through the organic solvent immobilized in the pores of the hollow fiber (organic phase), and further into the acceptor phase present inside the lumen of the hollow fiber. The analyte enrichment factor in this process can be calculated by the equation as follows: $E F=\left(V_{d} R\right) /\left(V_{a} \times 100\right)$, where $V_{a}$ is the volume of acceptor phase and $V_{d}$ is the volume of donor phase. It is clear that EFs were positively related to the ratio of $V_{d} / V_{a}$ from the equation. In the present work, keeping a constant donor phase volume of $4 \mathrm{~mL}$ with analyte concentration of $1 \mu \mathrm{g} / \mathrm{L}$, the effect of acceptor volume on EFs was studied in the range of 10-90 $\mu \mathrm{L}$. The results, shown in Fig. 3, illustrated EFs of five target analytes reaching maximum at $25 \mu \mathrm{L}$ of AP. The probable reason was that the small volume of acceptor phase would result in relatively high extraction efficiency $(R)$ and thus high enrichment factors. However, the enrichment factor could never become larger than the volume ratio of $V_{d} / V_{a}$. Therefore, $25 \mu \mathrm{L}$ of AP and $4 \mathrm{~mL}$ of DP were adopted in the following studies.

\subsection{Effect of stirring and shaking}

In order to accelerate the mass transfer velocity from donor through organic membrane into acceptor in the extraction, magnetic stirring and shaking are commonly used speedup means. Three speed rates $(50,150$, and $300 \mathrm{rpm})$ representing low, medium and high-speed respectively were investigated in experiments. The graphs (see AppendixBFig. S1 in Supplementary Material) indicated EFs markedly increased with the increasing of speed rates by both stirring and shaking. Nevertheless, stirring at the rate of $300 \mathrm{rpm}$ made the fiber spin intensively in the donor solution and as consequence, continuously produced air bubbles that attached to the fiber surface, resulting in slightly inferior repeatability (RSD\%: 



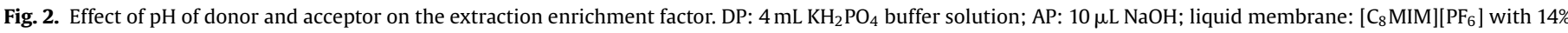
TOPO; shaking speed: $100 \mathrm{rpm}$; extraction time: $1 \mathrm{~h}$. ( $\square) \mathrm{SD} ;(\bigcirc) \mathrm{SM}_{1} ;(\triangle) \mathrm{SM}_{2} ;(\nabla) \mathrm{SMZ} ;(\triangleleft) \mathrm{SDM}$.

0.3-11.5\%) and lower EFs (18-35) than were obtained by shaking (RSD\%: 0.2-7.1\%; EFs: 22-41). Therefore, subsequent experiments were performed by shaking at $300 \mathrm{rpm}$.

\subsection{Effect of extraction time}

HF-LPME can be performed in the kinetic range or the equilibrium range. The $E F$ linearly increases with the increase of the extraction time in the first stage, whereas it becomes independent of the extraction time in the equilibrium range [35]. In three-phase HF-LPME, the amount of extracts should be expected to increase with the prolonged extraction time and reach maximum in the equilibrium stage. Fig. 4 displays the extraction time dependency for the equilibration of all analytes. As seen, the extraction of all analytes reached equilibrium after $8 \mathrm{~h}$. In most cases, HF-LPME is performed with extraction times approaching equilibrium to maximize recovery (typical extraction times of 30-90 min). The probable reason for the longer equilibrium time in the present work was that the relatively high viscosity of $\left[\mathrm{C}_{8} \mathrm{MIM}\right] \mathrm{PF}_{6}$ reduced mass transfer speed between donor and acceptor. On the other hand, the micropore structures of the hollow fiber would affect the molecules of SAs to transfer into the DP. Although the extraction time seemed relatively long, the repeatability of extraction was much better than

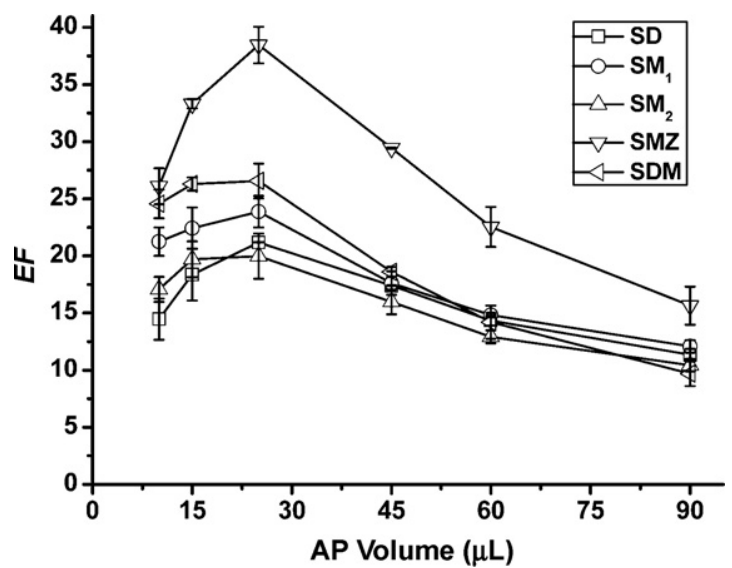

Fig. 3. Effect of volume ratio of donor to acceptor on the extraction enrichment factor. DP: $4 \mathrm{~mL}$, pH $4.5 \mathrm{KH}_{2} \mathrm{PO}_{4}$ buffer solution; AP: $0.25 \mathrm{M} \mathrm{NaOH}$; liquid membrane: [ $\left.\mathrm{C}_{8} \mathrm{MIM}\right]\left[\mathrm{PF}_{6}\right]$ with $14 \% \mathrm{TOPO}$; shaking speed: $100 \mathrm{rpm}$; extraction time: $1 \mathrm{~h}$. ( $\square$ ) SD; $(\bigcirc) \mathrm{SM}_{1} ;(\triangle) \mathrm{SM}_{2} ;(\nabla) \mathrm{SMZ} ;(\triangleleft) \mathrm{SDM}$. that with shorter extraction time. Meanwhile higher EFs (45-70) were obtained. Therefore, the extraction time of $8 \mathrm{~h}$ was chosen in further experiments.

\subsection{Effect of salt addition in donor phase}

In practicing conventional liquid-liquid extraction, the saltingout effect is often used to increase the partition coefficient of the polar analytes to the organic liquid. The effect in liquid-liquid extraction shows it is possible to promote dissolution of the analytes from the aqueous donor to the organic membrane liquid. According to the literatures, the effect of increasing ionic strength on the enrichment factor by addition of a salt is not beneficial for short extraction times, but for longer extractions [45]. Therefore, in this case, the content of salt added in the donor solution was varied to investigate its effect on the maximum EFs. The findings (Fig. 5) showed that the EFs for each compound increased with the increase of salt content. For SMZ and SDM, EFs did not increase significantly after the addition of $0.2 \mathrm{M} \mathrm{Na}_{2} \mathrm{SO}_{4}$. However, EFs of $\mathrm{SD}, \mathrm{SM}_{1}$ and $\mathrm{SM}_{2}$ increased remarkably with the content of $\mathrm{Na}_{2} \mathrm{SO}_{4}$ increasing and reached $128,135,100$ at $2 \mathrm{M} \mathrm{Na}_{2} \mathrm{SO}_{4}$ in donor phase, the concentration in which $\mathrm{Na}_{2} \mathrm{SO}_{4}$ is almost saturated at room temperature. This phenomenon could be explained by different

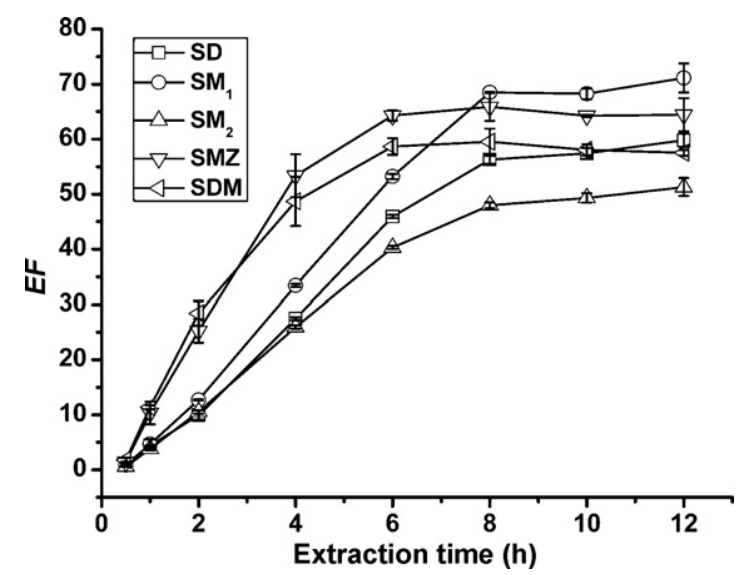

Fig. 4. Effect of extraction time on the extraction enrichment factor. DP: $4 \mathrm{~mL}$, pH 4.5 $\mathrm{KH}_{2} \mathrm{PO}_{4}$ buffer solution; AP: $25 \mu \mathrm{L}, 0.25 \mathrm{M} \mathrm{NaOH}$; liquid membrane: [ $\left.\mathrm{C}_{8} \mathrm{MIM}\right]\left[\mathrm{PF}_{6}\right.$ ] with $14 \%$ TOPO; shaking speed: $300 \mathrm{rpm}$. $(\square) \mathrm{SD}$; $(\bigcirc) \mathrm{SM}_{1} ;(\triangle) \mathrm{SM}_{2} ;(\nabla) \mathrm{SMZ} ;(\triangleleft)$ SDM. 
Table 3

Analytical performance of the proposed extraction procedure.

\begin{tabular}{|c|c|c|c|c|c|}
\hline Analytes & Linear range $(\mu \mathrm{g} / \mathrm{L})$ & Correlation equation & Correlation coefficient, $r$ & Enrichment factor & Detection limit $(\mu \mathrm{g} / \mathrm{L})$ \\
\hline SD & $1-2000$ & $y=6.5247 x+47.562$ & 0.9995 & 128 & 0.4 \\
\hline $\mathrm{SM}_{1}$ & $1-2000$ & $y=6.7724 x+67.747$ & 0.9997 & 135 & 0.1 \\
\hline $\mathrm{SM}_{2}$ & $1-2000$ & $y=6.232 x+67.338$ & 0.9997 & 100 & 0.3 \\
\hline SMZ & $1-2000$ & $y=5.6663 x+45.895$ & 0.9998 & 73 & 0.1 \\
\hline SDM & $1-2000$ & $y=2.8348 x+21.029$ & 0.9998 & 58 & 0.1 \\
\hline
\end{tabular}

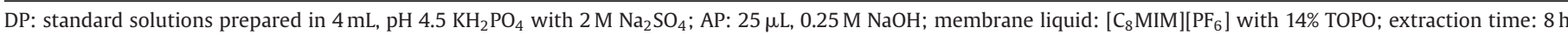
with shaking speed $300 \mathrm{rpm}$.

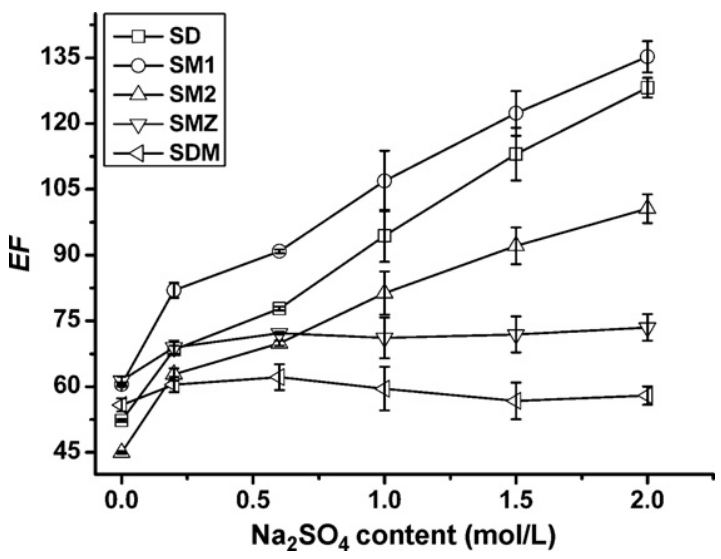

Fig. 5. Effect of sample salinity on the extraction enrichment factor. DP: $4 \mathrm{~mL}$, pH $4.5 \mathrm{KH}_{2} \mathrm{PO}_{4}$ buffer solution; AP: $25 \mu \mathrm{L}, 0.25 \mathrm{M} \mathrm{NaOH}$; liquid membrane [ $\left.\mathrm{C}_{8} \mathrm{MIM}\right]\left[\mathrm{PF}_{6}\right.$ ] with $14 \%$ TOPO; shaking speed: $300 \mathrm{rpm}$; extraction time: $8 \mathrm{~h}$. ( $\square) \mathrm{SD} ;(\bigcirc) \mathrm{SM}_{1} ;(\triangle)$ $\mathrm{SM}_{2} ;(\nabla) \mathrm{SMZ} ;(\triangleleft) \mathrm{SDM}$.

pKa and hydrophobic character of different compounds in donor solution. Because high salt content resulted in high EFs and was beneficial for longer extraction, $2 \mathrm{M} \mathrm{Na}_{2} \mathrm{SO}_{4}$ was added into the sample solution.

\subsection{Matrix effect}

Compounds with high molecular mass (such as humic acids that are commonly found in environmental matrices) are known to affect the ionization of lower mass molecules [46], and polar analytes such as sulfonamide antibiotics are the most susceptible to these effects [47]. Humic acid (0-25 $\mu \mathrm{g} / \mathrm{mL}$ DOC) and bovine serum albumin $(0-100 \mu \mathrm{g} / \mathrm{mL})$ as common high molecular compounds in environment and organisms were individually selected to study the matrix effect. The relative extraction efficiency was calculated by the peak area normalization method. The relative extraction efficiencies of all compounds were in the range of $97-104 \%$ and $98-113 \%$ over the studied concentration range of humic acid and BSA, respectively (see AppendixBFig. S2 in Supplementary Material). The results indicated there was no significant matrix effect on the relative extraction efficiencies of all the analytes.

\subsection{Method performance and real sample analysis}

Calibration curves of the method were plotted by 15 spiking levels in the range of $1-4000 \mu \mathrm{g} / \mathrm{L}$ for all compounds. Under the optimized conditions, wide linearity range $(1-2000 \mu \mathrm{g} / \mathrm{L})$, good correlative coefficients $(r=0.995-0.9998)$ and satisfactory enrichment factors (58-135) were obtained for the analytes. The limits of detection (LODs) were calculated at a signal-to-noise ratio of 3. The LODs $(\mu \mathrm{g} / \mathrm{L}$, with corresponding compounds in the parentheses) were $0.4(\mathrm{SD}), 0.1\left(\mathrm{SM}_{1}\right), 0.3\left(\mathrm{SM}_{2}\right), 0.1(\mathrm{SMZ})$, and 0.1 (SDM). Details about the parameters for the analytical performance of the proposed method can be found in Table 3. According to the research by Balakrishnan et al. [48], SPME and SPE were successfully employed for the determination of SAs. The LODs were respectively $9.04-55.3 \mu \mathrm{g} / \mathrm{L}$ of SPME and $2.88-9 \mathrm{ng} / \mathrm{L}$ of SPE. The SPME responses of sulfonamide antibiotics adhered to non-linear equations and all of studied SAs followed an excellent linear relationship with coefficients of determination $(r>0.97)$ by SPE. By a comparison of the performances of the present method with SPME and SPE, the sensitivities of HF-LPME were better than SPME and poorer than SPE; the LODs of HF-LPME were higher than SPME and lower than SPE. Whereas, the total sample volume required was $4 \mathrm{~mL}$ in the present work less than in SPE $(500 \mathrm{~mL})$ and the organic solvents was used in HF-LPME dozens of times less than in SPE. Therefore, it could be concluded that the present work was practicable for the determination of SAs in environmental water samples.

Five environmental water samples were analyzed to test the applicability of the proposed extraction procedure. One group of samples was extracted by the proposed procedure; the parallel group of samples was analyzed after spiking with $5 \mu \mathrm{g} / \mathrm{L}$ of target compounds. As shown in Table 4, only $\mathrm{SM}_{1}(0.12-0.26 \mu \mathrm{g} / \mathrm{L})$ and SDM $(0.15-0.22 \mu \mathrm{g} / \mathrm{L})$ were detected in wastewater from the pig and fish farm, whereas other compounds were not detected in any sample. Good spike recovery (82-103\%) was obtained. Moreover, the method displayed good reproducibility with RSD values in the range of $0.5-4.8 \%(n=3)$. Fig. 6 shows the HPLC chromatograms obtained by the proposed procedure: (a) $20 \mu \mathrm{g} / \mathrm{L}$ standard solution; (b) water sample spiked with $5 \mu \mathrm{g} / \mathrm{L}$ of each analyte; and (c) blank water sample. It was further demonstrated that the method showed effectively the interference free performance.

Table 4

Analyte concentration $\left(C_{0}, C_{s} \mu \mathrm{g} / \mathrm{L}\right)$ and spike recovery $(R=$ mean $\pm \mathrm{SD}, \%, n=3)$ in samples by the proposed method.

\begin{tabular}{|c|c|c|c|c|c|c|c|c|c|c|c|c|c|c|c|}
\hline \multirow[t]{2}{*}{ Samples } & \multicolumn{3}{|l|}{ SD } & \multicolumn{3}{|l|}{$\mathrm{SM}_{1}$} & \multicolumn{3}{|l|}{$\mathrm{SM}_{2}$} & \multicolumn{3}{|l|}{ SMZ } & \multicolumn{3}{|l|}{ SDM } \\
\hline & $C_{0}$ & $C_{s}$ & $R$ & $C_{0}$ & $C_{s}$ & $R$ & $C_{0}$ & $C_{s}$ & $R$ & $C_{0}$ & $C_{s}$ & $R$ & $C_{0}$ & $C_{s}$ & $R$ \\
\hline Wastewater $^{\mathrm{a}}$ & N.D. & 4.94 & $98.7 \pm 5.8$ & 0.12 & 5.24 & $102.4 \pm 6.4$ & N.D. & 4.67 & $93.3 \pm 8.6$ & N.D. & 4.46 & $89.1 \pm 6.7$ & 0.22 & 5.06 & $96.8 \pm 6.4$ \\
\hline Wastewater ${ }^{b}$ & N.D. & 5.04 & $82.5 \pm 7.2$ & 0.18 & 5.48 & $99.6 \pm 5.9$ & N.D. & 5.31 & $86.9 \pm 7.5$ & N.D. & 4.35 & $82.2 \pm 5.5$ & 0.15 & 4.72 & $91.4 \pm 8.7$ \\
\hline Duckery water & N.D. & 5.16 & $103.2 \pm 5.5$ & N.D. & 4.16 & $83.2 \pm 7.3$ & N.D. & 4.78 & $95.5 \pm 6.7$ & N.D. & 4.89 & $97.7 \pm 8.4$ & N.D. & 4.91 & $98.2 \pm 6.1$ \\
\hline Fishery water & N.D. & 4.75 & $95.0 \pm 6.3$ & 0.26 & 4.75 & $95.0 \pm 5.6$ & N.D. & 4.88 & $97.5 \pm 7.6$ & N.D. & 4.84 & $96.8 \pm 7.6$ & 0.2 & 4.92 & $94.3 \pm 6.9$ \\
\hline Paddy water & N.D. & 4.64 & $92.7 \pm 7.8$ & N.D. & 5.05 & $101.5 \pm 8.3$ & N.D. & 4.60 & $90.2 \pm 8.4$ & N.D. & 4.59 & $91.8 \pm 8.1$ & N.D. & 4.60 & $91.9 \pm 7.8$ \\
\hline
\end{tabular}

$C_{0}$ is the initial concentration of analytes without spike. $C_{s}$ is the concentration of analytes determined by spiking $5 \mu \mathrm{g} / \mathrm{L}$. N.D.: not detected.

a Collected from a sewage reservoir in the pig farm.

b Collected from a pool in the pig farm. 

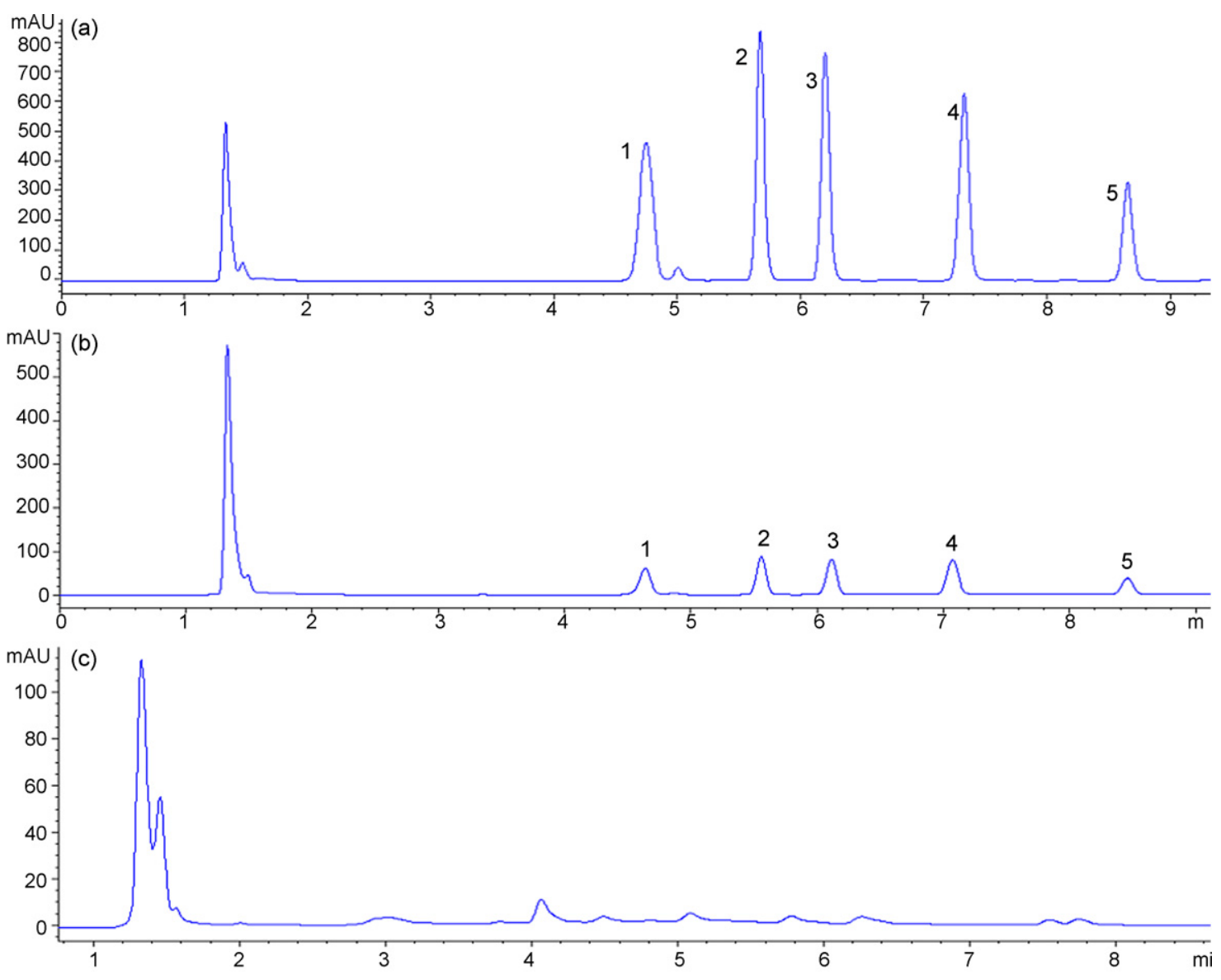

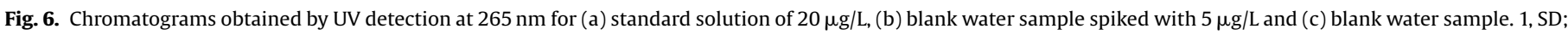
$2, \mathrm{SM}_{1} ; 3, \mathrm{SM}_{2} ; 4, \mathrm{SMZ} ; 5, \mathrm{SDM}$.

\section{Conclusions}

A hollow fiber supported ionic liquid based three-phase LPME was developed to detect trace level of amphoteric sulfonamides in environmental water samples. With the precise control of donor and acceptor $\mathrm{pH}$ and the addition of TOPO, as suitable additive into the ionic liquid membrane, the method provided high $E F$ s and combined extraction, enrichment and clean-up using small volume of samples in one step. In addition, ionic liquid as membrane phase would not only provide good extractability for SAs but also form an efficient barrier to big molecule compounds in complicated matrix. With few organic solvents being used in the total procedure, the proposed extraction procedure can be considered as an environmentally friendly, safe and simple technique for analyzing sulfonamides residues.

\section{Acknowledgements}

The present study was supported by the High-Tech Research and Development Program of China (2007AA06A413) and the National Natural Science Foundation of China (20621703, 20877082). X. H. acknowledges the support by the Key Project of Shanghai Natural Science Foundation (08JC1418900).

\section{Appendix A. Supplementary data}

Supplementary data associated with this article can be found, in the online version, at doi:10.1016/j.chroma.2009.06.025.

\section{References}

[1] K. Dost, D.C. Jones, G. Davidson, Analyst 125 (2000) 1243.

[2] W. Baran, J. Sochacka, W. Wardas, Ecotoxicol. Environ. Safe. 63 (2006) 113.

[3] K. Kümmerer, Chemosphere 45 (2001) 957.

[4] M. Carballa, F. Omil, J.M. Lema, M. Llompart, C. García-Jares, I. Rodríguez, M. Gómez, T. Ternes, Water Res. 38 (2004) 2918.

[5] N.A. Littlefield, W.G. Sheldon, R. Allen, D.W. Gaylor, Food Chem. Toxicol. 28 (1990) 157.

[6] M.S. Díaz-Cruz, M.J. López de Alda, D. Barceló, Trends Anal. Chem. 22 (2003) 340 .

[7] J. Jung, Y. Kim, J. Kim, D.H. Jeong, K. Choi, Ecotoxicology 17 (2008) 37.

[8] C.H. Huang, J.E. Renew, K.L. Smeby, K. Pinkston, D.L. Sedlak, The 2nd International Conference on Pharmaceuticals and Endocrine Disrupting Chemicals in Water, National Ground Water Association, Minneapolis, MN, USA, 2001.

[9] US FDA, Guidance for Industry: Environmental Assessment of Human Drug and Biologies Applications. CMC 6 Revision 1. Food and Drug Administration, Rockville, MD, 1998. Available at http://www.fda.gov/cder/guidance/1730fnl.pdf (last accessed 10/19/2004).

[10] EMEA, Draft CPMP discussion paper on environmental risk assessment of nongenetically modified organism (non-GMO) containing medicinal products for human use. CPMP/SWP.4447/00. European Agency for the Evaluation of Medicinal Products, London, 25 January 2001.

[11] N. Assassi, A. Tazerouti, J.P. Canselier, J. Chromatogr. A 1071 (2005) 71.

[12] A. Cannavan, S.A. Hewitt, W.J. Blanchflower, D.G. Kennedy, Analyst 121 (1996) 1457.

[13] B. Chiavarino, M.E. Crestoni, A. Di Marzio, S. Fornarini, J. Chromatogr. B 706 (1998) 269.

[14] C.Y. Lin, S.D. Huang, Anal. Chim. Acta 612 (2008) 37.

[15] G.Z. Fang, J.X. He, S. Wang, J. Chromatogr. A 1127 (2006) 12.

[16] J. Raich-Montiu, J. Folch, R. Compañó, M. Granados, M.D. Prat, J. Chromatogr. A 1172 (2007) 186.

[17] K.H. Lu, C.Y. Chen, M.R. Lee, Talanta 72 (2007) 1082.

[18] T. Li, Z.G. Shi, M.M. Zheng, Y.Q. Feng, J. Chromatogr. A 1205 (2008) 163

[19] L. Verzegnassi, M.C. Savoy-Perroud, R.H. Stadler, J. Chromatogr. A 977 (2002) 77.

[20] M.Y. Haller, S.R. Müller, C.S. McArdell, A.C. Alder Marc, J.F. Suter, J. Chromatogr. A 952 (2002) 111 
[21] G. Font, A. Juan-García, Y. Picó, J. Chromatogr. A 1159 (2007) 233.

[22] J. Raich-Montiu, J. Folch, R. Compañó, M. Granados, M.D. Prat, J. Chromatogr. A 1172 (2007) 186.

[23] S. Pedersen-Bjergaard, K.E. Rasmussen, Anal. Chem. 71 (1999) 2650.

[24] S. Pedersen-Bjergaard, K.E. Rasmussen, Electrophoresis 21 (2000) 579.

[25] T.G. Halvorsen, S. Pedersen-Bjergaard, K.E. Rasmussen, J. Chromatogr. A 909 (2001) 87.

[26] S. Pedersen-Bjergaard, T.S. Ho, K.E. Rasmussen, J. Sep. Sci. 25 (2002) 141.

[27] S. Andersen, T.G. Halvorsen, S. Pedersen-Bjergaard, J. Chromatogr. A 963 (2002) 303.

[28] K.E. Rasmussen, S. Pedersen-Bjergaard, M. Krogh, H.G. Ugland, T. GrPnhaug, J. Chromatogr. A 873 (2000) 3.

[29] T.S. Ho, S. Pedersen-Bjergaard, K.E. Rasmussen, J. Chromatogr. A 963 (2002) 3.

[30] T.G. Halvorsen, S. Pedersen-Bjergaard, K.E. Rasmussen, J. Chromatogr. B 760 (2001) 219.

[31] J.F. Liu, J.Á. Jönsson, G.B. Jiang, Trends Anal. Chem. 24 (2005) 20.

[32] R. Liu, J.F. Liu, Y.G. Yin, X.L. Hu, G.B. Jiang, Anal. Bioanal. Chem. 393 (2009) 871.

[33] J.F. Liu, G.B. Jiang, Y.G. Chi, Y.Q. Cai, Q.X. Zhou, J.T. Hu, Anal. Chem. 75 (2003) 5870.

[34] J.F. Liu, Y.G. Chi, G.B. Jiang, C. Tai, J.F. Peng, J.T. Hu, J. Chromatogr. A 1026 (2004) 143.
[35] R. Fortunato, C.A.M. Afonso, M.A.M. Reis, J.G. Crespo, J. Membr. Sci. 242 (2004) 197.

[36] J.F. Peng, J.F. Liu, X.L. Hu, G.B. Jiang, J. Chromatogr. A 1139 (2007) 165.

[37] J. Lezamiz, J.Á. Jönsson, J. Chromatogr. A 1152 (2007) 226.

[38] Y. Shen, V. Obuseng, L. Grönberg, J.Á. Jönsson, J. Chromatogr. A 725 (1996) 189.

[39] D.W. Kou, X.Y. Wang, S. Mitra, J. Chromatogr. A 1055 (2004) 63.

[40] G.H. Zhao, J.F. Liu, M. Nyman, J.Á. Jönsson, J. Chromatogr. B 846 (2007) 202.

[41] Y. Yamini, C.T. Reimann, A. Vatanara, J.Á. Jönsson, J. Chromatogr. A 1124 (2006) 57.

[42] A. Drapala, J.Á. Jönsson, P. Wieczorek, Anal. Chim. Acta 553 (2005) 9.

[43] R. Fortunato, C.A.M. Afonso, J. Benavente, E. Rodriguez-Castellón, J.G. Crespo, J. Membr. Sci. 256 (2005) 216.

[44] A. Pagliara, P.A. Carrupt, G. Caron, P. Gaillard, B. Testa, Chem. Rev. 97 (1997) 3385.

[45] L. Chimuka, N. Megersa, J. Norberg, L. Mathiasson, J.Á. Jönsson, Anal. Chem. 70 (1998) 3906

[46] J.L. Sterner, M.V. Johnston, G.R. Nicol, D.P. Ridge, J. Mass Spectrom. 35 (2000) 385.

[47] R. Bonfiglio, R.C. King, T.V. Olah, K. Merle, Rapid Commun. Mass Spectrom. 13 (1999) 1175

[48] V.K. Balakrishnan, K.A. Terry, J. Toito, J. Chromatogr. A 1131 (2006) 1. 